29 Pennington BF, van Doornick WJ, McCabe LL, McCabe ERB. Neuropsychological deficits in early treated phe-

30 Sattler JM. Organic brain damage. In: Assessment of children's intelligence. Philadelphia: Saunders, 1974:298-9.

31 Welsh MC. A prefrontal dysfunction model of early-treated phenylketonuria. Eur F Pediatr 1996;155(suppl 1):S87-9.

32 Huelsman CB. The WISC subtest syndrome for disabled readers. Percept Mot Skills 1970;30:535-50.

33 Hendrikx MMT, Vanderschot LWA, Slijper FME, Huisman J, Kalverboer AF. Phenylketonuria and some aspects of emotional development. Eur 7 Pediatr 1994;153:832-5.
34 Weglage J, Funders B, Ullrich K, Rupp A, Schmidt E. Psychosocial aspects of phenylketonuria. Eur $\mathcal{f}$ Pediatr chosocial aspects of phen

35 Holler KA, Fennell EB, Crosson B, Boggs SR, Mickle JP. Neuropsychological and adaptive functioning in younger versus older children shunted for early hydrocephalus. Child Neuropsychology 1995;1:6373

36 Thomasgard M, Metz WP, Edelbrock C, Shonkoff JP. Parent-child relationship disorders. 1. Parental overprotection and the development of the parent protection scale. $\mathcal{F}$ Dev Behav Pediatr 1995;16:244-50.

\title{
The limping child
}

Among the complaints that ring alarm bells in paediatricians' heads, back pain and a limp must come high on the list. The first prospective study of children presenting with a limp has been reported from Edinburgh (SU Fischer and TF Beattie. Fournal of Bone and Foint Surgery [Br] 1999;81-B:1029-34).

In the first six months of 1996, 244 children aged 1-14 years presented to the accident and emergency department of the Royal Hospital for Sick Children with a limp and no history of trauma. One child was excluded from analysis because of inadequate records. These children represented $0.18 \%$ of attendances and $63 \%$ of them were boys. Their median age was 4.35 years. About one third presented on the day of onset of the limp and $85 \%$ within a week of onset. A diagnosis was not made in 72 children (30\%). The most common final diagnoses were transient synovitis (23\%), irritable hip $(16 \%)$, and soft tissue injury or muscular strain (16\%). Perthes' disease, osteomyelitis, and slipped femoral capital epiphysis occurred in five, four, and one of the 243 patients. There is no mention of non-accidental injury.

Assessment included full clinical examination and usually full blood count and erythrocyte sedimentation rate (ESR). If the problem appeared to be in the hip, ultrasonography was performed by a consultant radiologist; $x$ rays were obtained as clinically indicated. After making a working diagnosis, $20 \%$ of children were discharged without follow up, $57 \%$ were followed up in the accident and emergency department, $12 \%$ were referred for speciality follow up, and $12 \%$ were admitted to hospital. A diagnosis was missed on first assessment in three children: two developed osteomyelitis but neither of them had had the full blood count and ESR required by protocol, another child had Langerhans' cell histiocytosis diagnosed radiologically after he had left the department.

With careful assessment in the emergency department most children presenting with a limp do not need to be admitted to hospital.

ARCHIVIST 